\title{
Correction to: The AHR represses nucleotide excision repair and apoptosis and contributes to UV-induced skin carcinogenesis
}

\author{
Marius Pollet ${ }^{1} \cdot$ Siraz Shaik ${ }^{1} \cdot$ Melina Mescher ${ }^{1} \cdot$ Katrin Frauenstein $^{1} \cdot$ Julia Tigges $^{1} \cdot$ Stephan A. Braun $^{2}$. \\ Kevin Sondenheimer ${ }^{1}$ - Mana Kaveh ${ }^{1} \cdot$ Anika Bruhs $^{3} \cdot$ Stephan Meller ${ }^{2} \cdot$ Bernhard Homey $^{2}$ - Agatha Schwarz ${ }^{3}$. \\ Charlotte Esser $^{1} \cdot$ Thierry Douki $^{4} \cdot$ Christoph F. A. Vogel $^{5}$. Jean Krutmann ${ }^{1} \cdot$ Thomas Haarmann-Stemmann $^{1}$
}

Published online: 22 October 2019

(c) The Author(s), under exclusive licence to ADMC Associazione Differenziamento e Morte Cellulare 2019

\section{Correction to: Cell Death \& Differentiation}

https://doi.org/10.1038/s41418-018-0160-1

The original PDF version of this article incorrectly showed the copyright holder to be "ADMC Associazione
Differenziamento e Morte Cellulare 2018', when the correct copyright holder is 'The Authors 2018'. This has been corrected in the PDF version of the article. The HTML version was correct from the time of publication.

Thomas Haarmann-Stemmann

thomas.haarmann-stemmann@iuf-duesseldorf.de

1 IUF_Leibniz-Research Institute for Environmental Medicine, 40225 Düsseldorf, Germany

2 Department of Dermatology, Medical Faculty, Heinrich-Heine University, 40225 Düsseldorf, Germany

3 Department of Dermatology and Allergology, Kiel University, 24105 Kiel, Germany

4 University Grenoble Alpes, INAC, CNRS, SyMMES UMR 3819, F-38000 Grenoble, France

5 Department of Environmental Toxicology and Center for Health and the Environment, University of California, Davis, CA 95616, USA 